\title{
MOVIE SUCCESS PREDICTION USING RECOMMENDATION TECHNIQUES
}

\author{
R. Vignesh D. Deepa, B. Keerthi Samhitha, Suja Cherukullapurath Mana, \\ Jithina Jose and M.S. Roobini \\ Assistant Professor, Department of Computer Science and Engineering, \\ Sathyabama Institute of Science and Technology, Chennai, India
}

\begin{abstract}
A film advice is vital in our social lifestyles due to its electricity in presenting more suitable leisure. One of these gadget can recommend a hard and fast of films to customers founded totally on their hobby, or the popularities of the films. Even though, a set of movie advice systems were proposed most of these both can't suggest a film to the existing customers effectively or to a new consumer. On this paper we advocate a film advice network that has capability to suggest films to a recent consumer also the others. It mines film databases to that have to gather all of the important information, which include reputation and attractiveness, required for recommendation. It generates film swarms no longer handiest handy for film producer to plot a new brand film but also useful for movie recommendation

Experimental research on the real statistics displays the performan and effectiveness of the proposed machine.

Key words: Movie id, Customer id, Timestamp, Rating.

Cite this Article: R. Vignesh D. Deepa, B. Keerthi Samhitha, Suja Cherukullapurath Mana, Jithina Jose and M.S. Roobini, Movie Success Prediction Using Recommendation Techniques. International Journal of Electrical Engineering and Technology, 11(4), 2020, pp. 422-426.

https://iaeme.com/Home/issue/IJEET?Volume $=11 \&$ Issue $=4$
\end{abstract}

\section{INTRODUCTION}

Recommendation systems assist customers discover and choose objects (e.g., records, cinemas) from the vast quantity obtainable on the net or in more digital details assets. Stated a massive place of objects and a report of the person's requirement, they gift to the person a tiny place of the objects which are properly accepted to the outline. Equally, a film advice device offers a degree of ease and personalization that support the customer engage higher with the network and view films that serve to his desires. The leading goal of our device will also endorse diverse to its customers rest on their spot records and scores that they offer. The network will also endorse diverse E-commerce business to reveal their merchandises to particular clients primarily rest on the lifestyle of films they prefer. Customized suggestion 
agents assist heaps of persons slender the space of capacity pictures to adequate their exclusive suggest. Collaborative filtering and content based filtering are the key methods to offer suggestion to customers. Each of them are first-class apt in precise scripts due to their relevant ups and downs. we have got presented a k-nearest neighbor which comes below gadget studying algorithms to enhance the performance and accuracy of device.

\section{RELATED WORK}

In 2017, Tayeb Himel[1] There are a diverse set of products for a selected type on the net. While any customer tries to find out fine product amongst a positive kind it is miles very a great deal difficult to do it yourself go through every one among them. That's why manually looking is not always very efficient. In that scenario, recommendation machine performs an excessive crucial position to recommend the first-rate products. In this examine, we established a recommendation system for the group that works with films. Our recommendation system advice films based on customer data.

In 2018, Jeffrey Lund[2] Recommendation systems are an vital portion of proposing objects specially in streaming facilities. For streaming movie services like Netflix, recommendation systems are crucial for advising customers discover new cinemas to delight in. In this notepaper.

We settle further a deep learning approach established on auto encoders to produce a collaborative filtering system which predicts film ratings for a person based on a huge database of ratings from other users. Usage of MovieLens dataset, we determine by means of of deep learning to foresee customers' ratings on different big screen, thereby allowing movie recommendations.

In 2018, Ching-She[3] As the business needs are fast, there's an enlarged weakness on removing purposeful data from banging quantity of data to guide industry way out. The identical is correct for digital suggestion networks that are turned into the rule for shopper industries which include books, music, clothing, movies, news articles, places, utilities, etc. These systems gather the data from the customers to expand the long run tips.

In 2017, Rajan Subramaniam[4] A suggestion network offers a personal with customized favour. This notepaper explains our analysis managed to establish and execute a moving picture machine with in the kind of an internet application exploitation using two easy approaches: (1) Non-Personalized suggestion, (2) Content based mostly suggestion techniques employing a machine-learning algorithmic rule.

\section{SYSTEM ANALYSIS}

Collaborative filtering mimics customer-to-customer recommendations. It predicts customer's preferences as a linear, weighted combination of other customer preferences.

Content-based filtering can recommend a new item, but needs more data of customer preference in order to incorporate best match. A suggestion technique filters the information exploitation totally different algorithms and suggests the foremost apt things to customers. It 1 st captures the foregone action of a client and supported that, suggests results, Ease to interpret output, Less Calculation time, Predictive Power. 


\section{SYSTEM DESIGN}

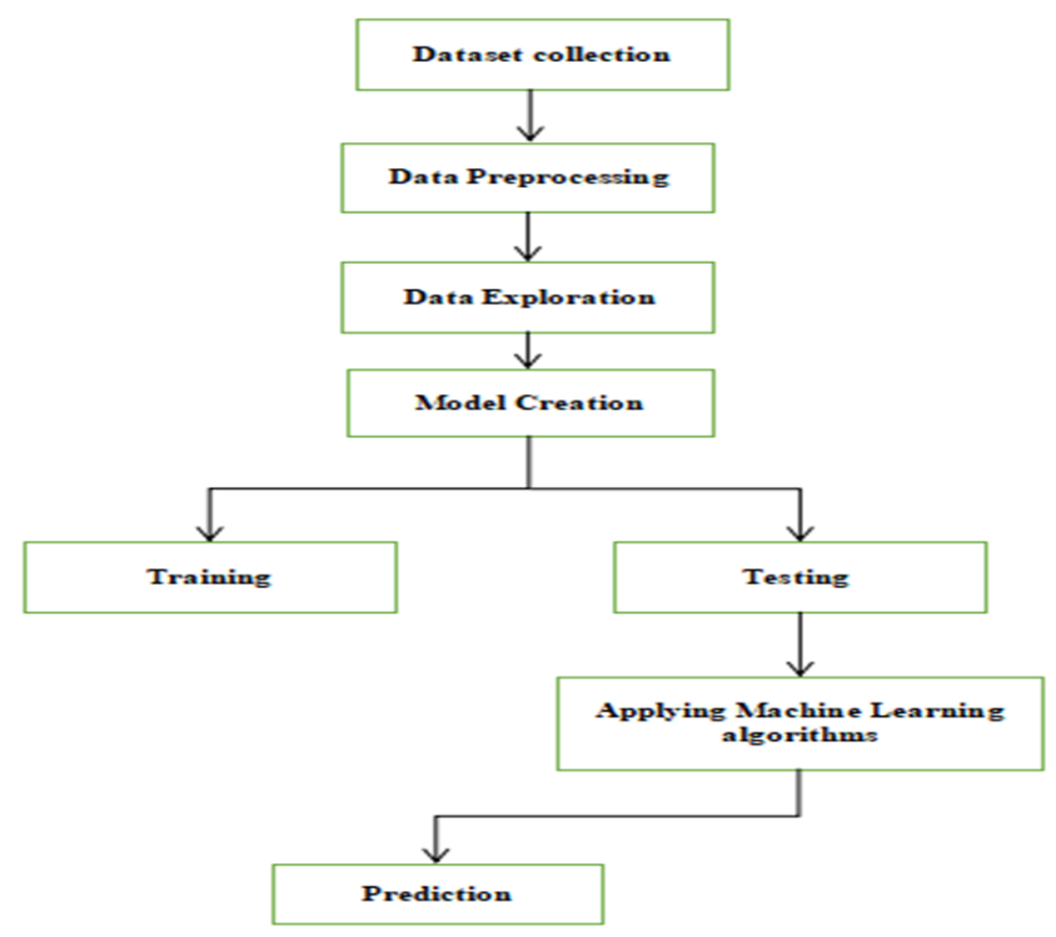

Figure 1 System Design

A suggestion network may be a platform that gives its customers with varied contents supported their preferences and likings. A recommendation system takes the data concerning the client as associate degree input. Advocating system is associate degree implementation of the machine learning algorithms Content-based filtering approaches uses a series of separate characteristics of associate degree item so as to recommend further things with similar properties. These strategies area unit all supported an outline of the item and a profile of the customer's preferences. It recommends things supported customer's past preferences.

\section{METHODOLOGY}

This is the initial stage which convert our raw data into cleaned data. When collecting data from different source which is not in proper format it is not feasible for better prediction. A way of those vast file position may be a sizable amount of elements that need tons of calculating materials to activity. Theme obtaining is that the title for systems that fix or mingle elements into themes.

\section{RESULT}

In the below graph, the $\mathrm{X}$-axis represents the Movie and the $\mathrm{Y}$-axis represents the ratings of that movie. It explains that the movie can be recommended according to ratings based on the movie Id. 


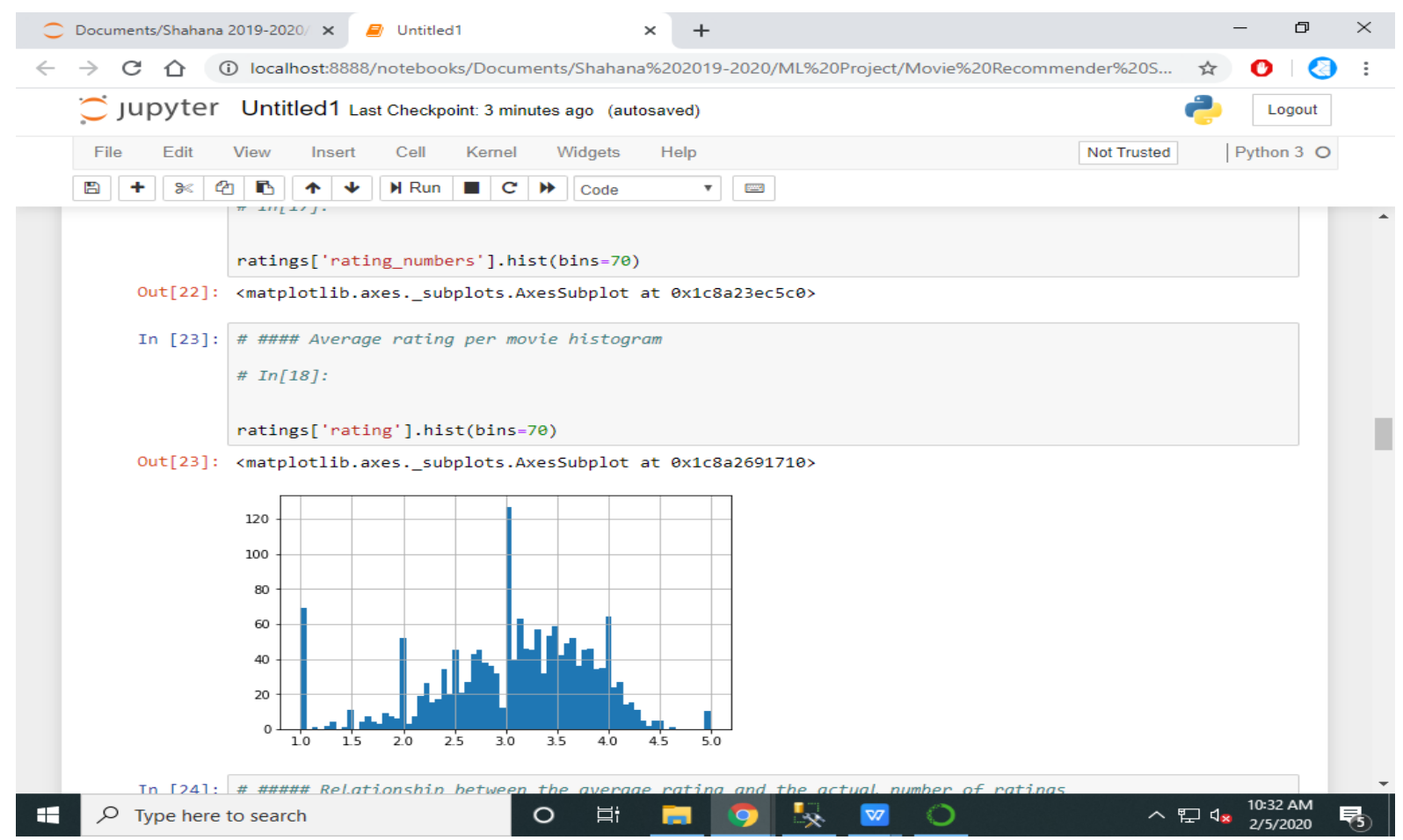

Figure 2 Graph

\section{CONCLUSION}

Here, recommendation technique algorithm is used to guess customer's movie rating. The MovieLens dataset, that has 10 million ratings, is choosen in our project and splited into coaching set and take a look at set. The RMSE method is used for formula analysis. In step with analysis output, our film suggestion network has lovely sensible forecast presentation.

\section{REFERENCES}

[1] Movie Recommender System Using K-Means Clustering and K-Nearest Neighbor, Rishabh Ahuja; Arun Solanki; Anand Nayyar, (2019) 9th International Conference on Cloud Computing, Data Science \& Engineering (Confluence)

[2] Movie Recommendation Using Metadata Based Word2Vec Algorithm, Yeo Chan Yoon; Jun Woo Lee, (2018) international conference

[3] Movie Master: Hybrid Movie Recommendation System Method, Rajan Sri Subramaniam; Roger; Tokuro Matsuo, (2017) International System Conference on Computational Science and Intelligence System Technology.

[4] Deep Mov RS: (2017) A unified framework for deep mechine learning-based movie recommender systems, S.M Taheri; Iman Irajian, 2018 6th Iranian Joint Congress on fuzzy and intelligent Systemmovie Recommendations. Simulation of genre based movie recommendation system using Hadoop MapReduce technique, Goral K. Godhani; Maulik Dhamecha, 2017 International(ICECDS)

[5] Evaluation of Naïve Bayes and Support Vector Machines on Bangla Textual Movie Reviews, Nayan Banik; 2018 International Conference on Bangla Speech and Language pre-Processing (ICBSLP)

[6] R. Vignesh, D. Deepa, P. Anitha, S. Divya and S. Roobini, (2020) "Dynamic Enforcement of Causal Consistency for a Geo-replicated Cloud Storage System”, International Journal of Electrical Engineering and Technology, 11(3), pp. 181- 
[7] R.Vignesh, K.Mohana Prasad, (2019) "Cloud-Implementation of E-Healthcare Framework", International Journal of Recent Technology and Engineering (IJRTE) ISSN: 2277-3878, Volume-8 Issue-3, September

[8] Divya.S., R. Vignesh., Revathy, R. (2019) "A Distincitve Model to Classify Tumor Using Random Forest Classifier", Proceedings of the 3rd International Conference on Inventive Systems and Control, ICISC

[9] Vignesh Ramamoorthy, S. Divya, Suja Cherukullapurath Mana and B. Keerthi Samhitha," Examining and Sensing of Artificial Knee with Multi Sensors Networks", Journal of Advanced Research in Dynamical and Control Systems(JARDCS),10(4),115-120.

[10] Deepa D, R. Vignesh, Sivasangari A, Suja Cherukullapurath Mana, B. Keerthi Samhitha and Jithina Jose, (2020) Visualizing Road Damage by Monitoring System in Cloud. International Journal of Electrical Engineering and Technology, 11(4), pp. 191-203

[11] Jithina Jose, Suja Cherukullapurath Mana, B. Keerthi Samhitha, (2019) "An Efficient System to Predict and Analyze Stock Data using Hadoop Techniques", International Journal of Recent Technology and Engineering (IJRTE) ISSN: 2277-3878, Volume-8 Issue-2, July

[12] Samhitha, B.K., Mana, S.C., Jose, J., Mohith, M., Siva Chandhrahasa Reddy, L. (2019)" An efficient implementation of a method to detect sybil attacks in vehicular adhoc networks using received signal strength indicator", International Journal of Innovative Technology and Exploring Engineering, (IJITEE) ISSN: 2278-3075, Volume-9 Issue-1, November

[13] Mana, S.C., Samhitha, B.K., Jose, J., Swaroop, M.V., Reddy, P.C.K. (2019) "Traffic violation detection using principal component analysis and viola jones algorithms "International Journal of Recent Technology and Engineering (IJRTE) ISSN: 2277-3878, Volume-8 Issue-3, September

[14] Mana, S.C., Sasipraba, T. (2019) "Highly parallel map reduce process and efficient job scheduling methodologies of big data systems" International Journal of Innovative Technology and Exploring Engineering, ISSN: 2278-3075 ,Volume-9 Issue-1, November

[15] B. Keerthi Samhitha , Suja Cherukullapurath Mana, Jithina Jose , R.Vignesh, D. Deepa" (2020) Prediction of Lung Cancer Using Convolutional Neural Network (CNN)" International Journal of Advanced Trends in Computer Science and Engineering 9(3):33613365, June

[16] Ishwarya, M.V., Deepa, D., Hemalatha, S., Nynesh, A.V.S., Tej, A.P., (2019) " Gridlock surveillance and management system" 16(8):3281-3284, Journal of Computational and Theoretical Nanoscience, August 